\title{
Anatomical variation of the ulnar artery: clinical and developmental significance
}

\author{
GHOSH, B. ${ }^{1 *}$, YADAV, S. ${ }^{1}$, BUDHIRAJA, V. ${ }^{2}$, DASS, P. K. ${ }^{1}$, RASTOGI, R. ${ }^{2}$ and \\ CHOWDHURY, S. ${ }^{3}$
}

\author{
${ }^{1}$ Department of Anatomy, Dr. Rajendra Prasad Government Medical College, Tanda, Kangra, \\ Himachal Pradesh, India \\ ${ }^{2}$ Department of Anatomy, L.N. Medical College, Bhopal, M.P, India \\ ${ }^{3}$ PGT Biology, Kendriya Vidyalaya, Dharmashala Cantt, Himachal Pradesh, India \\ *E-mail: debanatomy@gmail.com
}

\begin{abstract}
Introduction: Variation of the ulnar artery in the upper limb is uncommon. The existence of such a variant is of particular clinical significance, as these arteries are more susceptible to trauma, and can be easily confused with superficial veins during medical and surgical procedures, potentially leading to iatrogenic distal limb ischemia. Case report: During routine dissection we observed a unilateral case of superficial ulnar artery in a 60 -year-old male cadaver. It originated from the left brachial artery in the middle of the arm, near to insertion of coracobrachialis muscle. From its origin, it passed downwards in the medial part of arm behind the median nerve and forearm in a superficial plane compared to normal ulnar artery. In the hand, the superficial ulnar artery anastomosed with the palmar branch of the radial artery, creating the superficial palmar arch. Brachial artery divided into the radial and common interosseous arteries in the cubital fossa. The normal ulnar artery was absent. The existence of superficial ulnar artery is undeniably of interest to the clinicians as well as to the anatomists.
\end{abstract}

Keywords: brachial artery, superficial ulnar artery, vascular variation, radial artery, superficial palmar arch.

\section{Introduction}

Brachial artery is a continuation of axillary artery at the lower border of teres major muscle. It usually terminates at the level of neck of radius in the cubital fossa by dividing into radial and ulnar arteries (STANDRING, BORLEY and COLLINS 2008). Variations of the arterial patterns in the upper limb have been the subject of many anatomical studies due to their high incidence. Usually, the ulnar artery gives off the common interosseous artery that divides into the anterior and posterior interosseous arteries (RODRIGUEZ-NIEDENFUHR, VAZQUEZ, NEARN et al., 2001). The ulnar artery passes medially deep to the pronator teres muscle and then runs to the distal part of the forearm together with the ulnar nerve. In the distal half of the forearm, it proceeds between the flexor carpi ulnaris and flexor digitorum superficialis muscles, being covered by the skin and fascia. The artery ends anterior to the flexor retinaculum by dividing into two terminal branches. The superficial one forms the superficial palmar arch (SPA) with a contribution from the superficial branch of the radial artery and the deep branch anastomoses with the radial artery to form the deep palmar arch (VOLLALA, JETTI and SONI, 2011). A superficial ulnar artery (SUA) is an ulnar artery of high origin that lies superficially in the forearm. Its reported frequency ranges from $0.17 \%$ to $2 \%$. It usually arises higher up than the superficial palmar arch (SPA), either in the axilla or the arm, and runs a superficial course in the forearm before entering the hand (NATSIS, PAPADOPOULOU, PARASKEVAS et al., 2006). One variant of superficial ulnar arteries is the superficial brachioulnar artery (SuBUA), which is defined as an ulnar artery with a high origin in the arm that progresses over the superficial muscles of the forearm. The overall prevalence of this variant is estimated to be around 2.7\% (RODRIGUEZNIEDENFUHR, VAZQUEZ, NEARN et al., 2001). A sound knowledge of the vascular anatomy of the upper limb is of paramount importance, since this is a site of frequent injury and of various surgical and invasive procedures (JACQUEMIN, LEMAIRE, MEDOT et al., 2001).

\section{Case Report}

During routine dissection of upper limb in the Department of Anatomy, Dr. Rajendra Prasad Government Medical College, India, unusual high origin of ulnar artery and its abnormal superficial course in the arm and forearm was observed in 60 -year-old male cadaver. There was no history or evidence of any invasive procedure in the upper limbs of that person. In the left upper limb of the cadaver, the brachial artery ended at its normal level of termination by dividing into radial and common interosseous arteries at the cubital fossa (Figure 1,2).

The radial artery took a normal course. The common interosseous artery passed deep to the pronator teres muscle giving off, posterior interosseous and anterior interosseous branches (Figure 2). The ulnar artery (superficial ulnar artery) originated from the brachial artery in the middle of the arm near to insertion of coracobrachialis muscle (Figure 1). From this point of high origin, the ulnar artery descended posterior to the median nerve initially, and then ran medial to it in the distal part of arm in a superficial plane. Then it 
descended on the medial aspect of front of the forearm, there were no branches throughout its course in the forearm and it was running superficial to the deep fascia. It failed to give common interosseous, posterior ulnar recurrent, palmar carpal and dorsal carpal branches. Proximal to the flexor retinaculum, it was accompanied by the ulnar nerve with which it descended in front of the retinaculum to reach the palm. In the palm it continued as superficial palmar arch after giving a deep branch (Figure 3).

\section{Discussion}

Ulnar artery variations are reported from its high origin from axillary artery or from brachial artery in the arm and its superficial course in the arm and forearm (BHAT, POTU, GOWDA, 2008; KITHSIRI, SENANAYAKE, RATHNAYAKE et al., 2007). The occurrence of such superficial ulnar arteries in cadavers is reported to be $9.12 \%$ (DEVANSH, 1996). There are reports of SUA coursing superficial and deep to bicipital

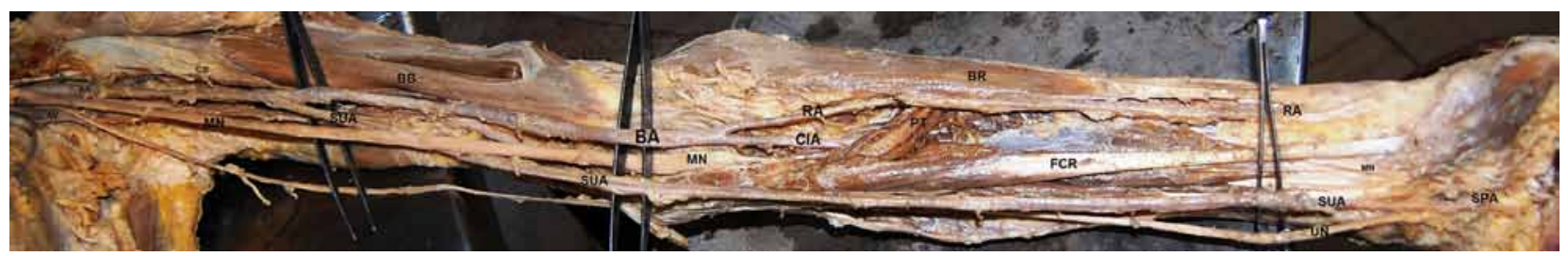

Figure 1. Dissection of the anterior compartment of upper limb showing the high origin of superficial ulnar artery (SUA) from the brachial artery (BA); Median nerve (MN) and biceps brachii muscle (BB); Axillary artery (AA); Axillary vein (AV); Musculocutaneous nerve (MCN); Coracobrachialis Muscle (CB); Radial Artery (RA); Common interosseous artery (CIA); Pronator Teres (PT); Flexor carpi radialis tendon (FCR); Ulnar nerve (UN); Brachioradialis muscle (BR); superficial palmar arch (SPA).

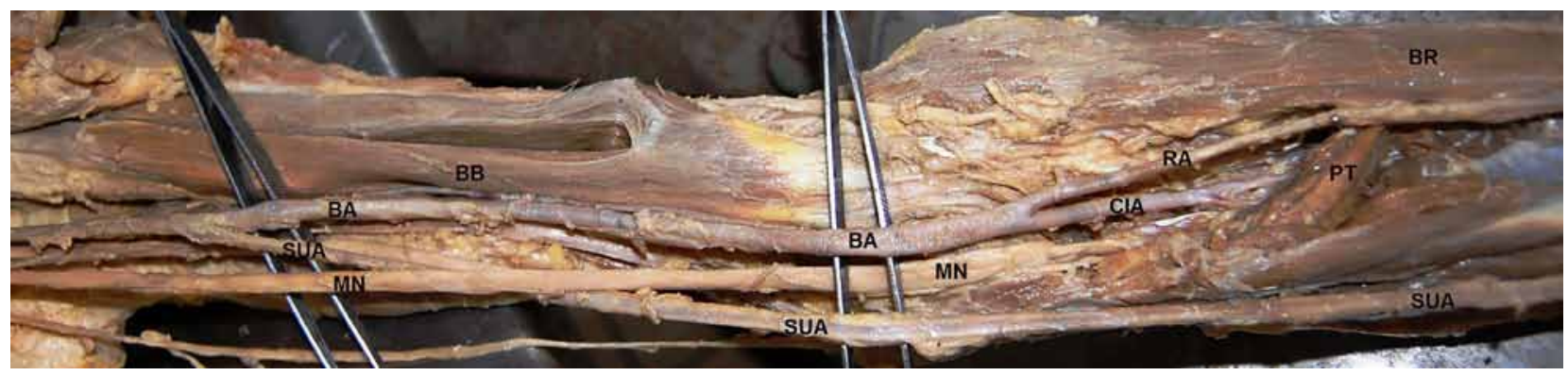

Figure 2. Dissection of the cubital region showing the superficial course of superficial ulnar artery (SUA); Brachial artery (BA); Median nerve (MN) and biceps brachii muscle (BB); Radial Artery (RA); Common interosseous artery (CIA); Pronator Teres (PT); Brachioradialis muscle (BR).

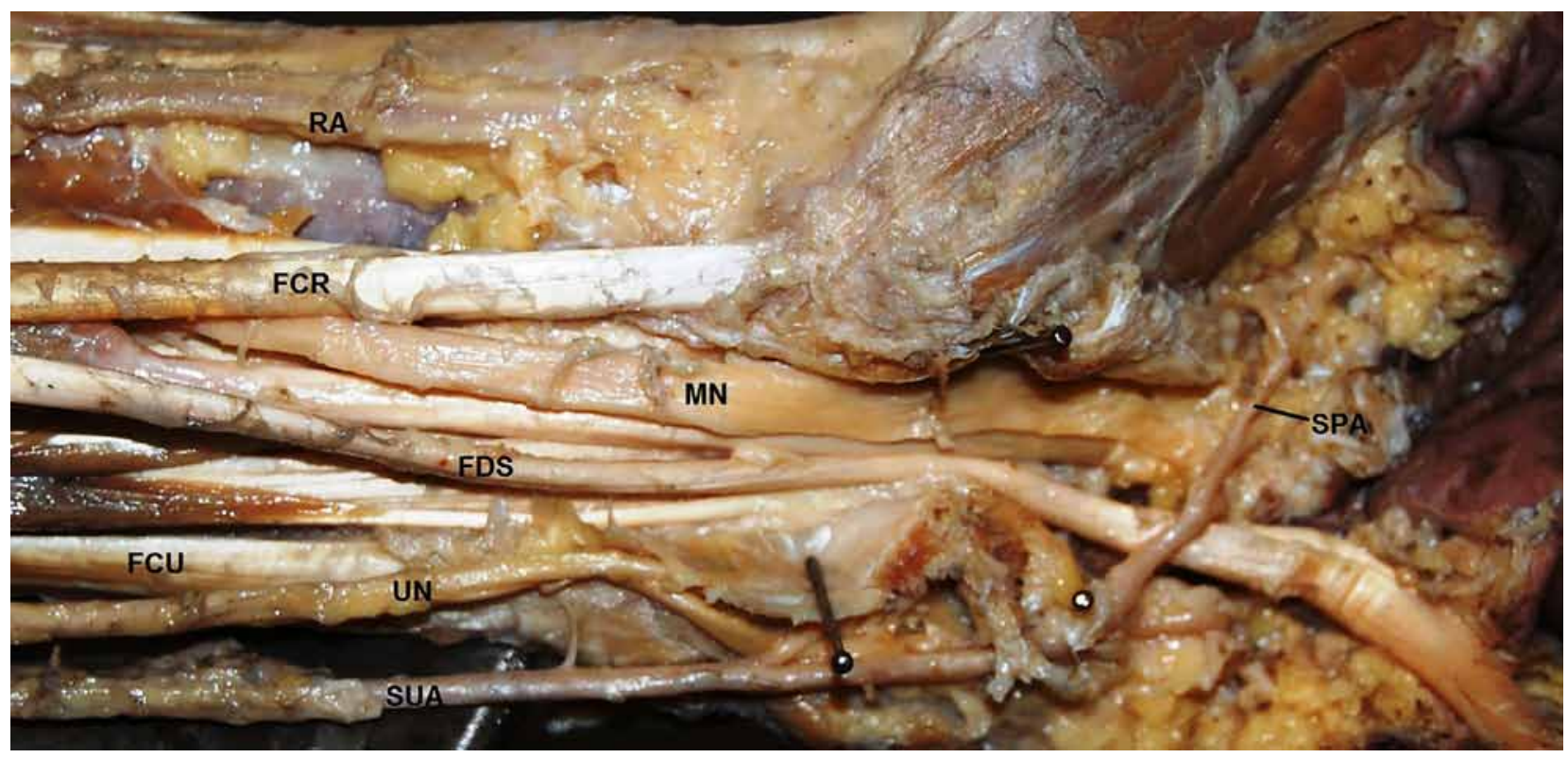

Figure 3. Dissection of the distal part of the front of forearm and the palm showing the superficial palmar arch (SPA) formed by the superficial ulnar artery (SUA); Radial Artery (RA); Flexor carpi radialis tendon (FCR); Flexor digitorum superficialis (FDS); Flexor carpi ulnaris (FCU); Ulnar nerve (UN); Median nerve (MN). 
aponeurosis (BHAT, POTU, GOWDA, 2008; KITHSIRI, SENANAYAKE, RATHNAYAKE et al., 2007). Its clinical importance should not be underestimated as several cases of intra-arterial injection of drugs and subsequent amputations have been reported (OHANA, SHEINER, GURMAN, 1999). A case of bilateral SUA originating from axillary artery has been reported. In the left limb, it branched directly from the axillary artery and in the right limb, the SUA originated in common with the subscapular artery (JACQUEMIN, LEMAIRE, MEDOT et al., 2001). Accidental cannulation of such variant artery by an ignorant clinician may lead to ischemia of the hand. It is essential for the surgeons to be aware of such variant vessels and adapt the surgical procedure accordingly, especially during radial forearm flaps (DARTNELL, SEKARAN, ELLIS, 2007) The possibility of superficial arteries getting mistaken for superficial veins is also well reported (KITHSIRI, SENANAYAKE, RATHNAYAKE et al., 2007).Such mistakes might lead to intra-arterial injections, wrong interpretations of incomplete angiographic images or severe disturbances of hard irrigation during surgical procedures on the arm or forearm (KITHSIRI, SENANAYAKE, RATHNAYAKE et al., 2007). Possible impairment of the SUA by mistake during harvesting of fascio cutaneous forearm flaps has been reported by Sieg, Jacobsen, Hakim et al. (2006). They report that SUA is a calculable anatomic variation as long as it's possible presence is considered during flap harvesting and in such cases; the use of SUA flap is an easy and safe alternative (SIEG, JACOBSEN, HAKIM et al., 2006). By careful palpation or by using vascular doppler, the presence of SUA and its course can be diagnosed preoperatively and accidental division of these vessels during the raising of the radial forearm flap can be avoided (DEVANSH, 1996). Developmentally, the upper limb bud is initially supplied by a vascular plexus derived from four or five consecutive intersegmental branches of the dorsal aorta. Very early in development, the seventh cervical intersegmental branch enlarges and becomes consolidated as the main artery (axis artery) to the developing upper limb bud. This axis artery gives rise to the subclavian, axillary, brachial, and interosseous arteries and to the deep palmar arch. Other arteries of the upper limb develop as sprouts of the axis artery (VOLLALA, JETTI and SONI, 2011).Because of this temporal succession of emergence of principle arteries, anomalies of forearm vasculature occur (KITHSIRI, SENANAYAKE, RATHNAYAKE et al., 2007). This sprouting theory is greatly challenged by the study of Rodriguez-Niedenfuhr, Vazquez, Nearn et al. (2001). Their findings suggest that the arterial pattern of the upper limb develops from an initial capillary plexus by a proximal and distal differentiation, due to maintenance, enlargement and differentiation of certain capillary vessels, and the regression of others. The embryological basis of arterial variations could be described by modification of normal capillary maintenance and regression (RODRIGUEZ-NIEDENFUHR, VAZQUEZ, NEARN et al., 2001). The developmental reason for the superficial ulnar artery in the present case may be due to the ulnar artery establishing a connection with the axis artery in the arm and the bifurcation of the brachial artery into the radial artery and common interosseous artery may be due to the posterior interosseous artery arising from the axis artery just distal to the connection of the radial artery with the axis artery in the cubital fossa region and the continuation of the main trunk (axis artery) between the radial and posterior interosseous arteries being the common interosseous artery.

\section{Conclusion}

Variation of the ulnar artery and its high origin and superficial course (SUA) is rare with immense clinical importance for the proper diagnosis and planning of operative treatment of forearm and hand surgeries. The knowledge of such variation is important; not only for surgeons but also for other medical and nursing staff because intravascular canulations are commonly performed by them. Variation in the branching pattern of the brachial artery is of significance in cardiac catheterization for angioplasty, pedicle flaps, arterial grafting or brachial pulse. It is important for surgeons, clinicians and anatomists to be aware of possible anatomical variations to avoid unexpected complications.

Acknowledgements: The authors wish to thank Mr.Chaman Sen Senior Lab Technician and Mr.Balakram photographer of Anatomy department for the illustrations.

\section{References}

BHAT, KM., POTU, BK. and GOWDA, S. High origin of ulnar artery in South Indian male cadaver: a case report. Romanian Journal of Morphological Embryology, 2008, vol. 49, n. 4, p. 573-575.

DARTNELL, J., SEKARAN, P. and ELLIS, H. The superficial ulnar artery: incidence and calibre in 95 cadaveric specimens. Clinical Anatomy (New York, N.Y.), 2007, vol. 20, n. 8, p. 929-932.

DEVANSH. Superficial ulnar artery flap. Plastic and Reconstructive Surgery, 1996, vol. 97, n. 2, p. 420-426.

JACQUEMIN, G., LEMAIRE, V., MEDOT, M. and FISSETTE, J. Bilateral case of superficial ulnar artery originating from axillary artery. Surgical and Radiologic Anatomy, 2001, vol. 23, n. 2, p. 139-143.

KITHSIRI, J., SENANAYAKE, SS., RATHNAYAKE, MJ., FERNANDO, $\mathrm{R}$. and SOMARATHNE, K. A rare variant of the superficial ulnar artery, and its clinical implications: a case report. Journal of Medical Case Reports, 2007, vol. 1, p. 128.

NATSIS, K., PAPADOPOULOU, AL., PARASKEVAS, G., TOTLIS, T. and TSIKARAS, P. High origin of a superficial ulnar artery arising from the axillary artery: anatomy, embryology, clinical significance and a review of the literature. Folia Morphologica, 2006, vol. 65, p. 400-405.

OHANA, E., SHEINER, E. and GURMAN, GM. Accidental intraarterial injection of propofol. European Journal of Anaesthesiology, 1999, vol. 16, p. 569-570.

RODRIGUEZ-NIEDENFUHR, M., VAZQUEZ, T., NEARN, L., FERREIRA, B., PARKIN, I. and SANUDO, JR. Variations of the arterial pattern in the upper limb revisited: a morphological and statistical study, with a review of the literature. Journal of Anatomy, 2001, vol. 199, p. 547-566.

SIEG, P., JACOBSEN, HC., HAKIM, SG. and HERMES, D. Superficial ulnar artery: curse or blessing in harvesting fasciocutaneous forearm flaps. Head $\ll$ Neck, 2006, vol. 28, n. 5, p. 447-452.

STANDRING, S., BORLEY, NR. and COLLINS, P. Gray's anatomy: the anatomical basis of clinical practice. 40th ed. London: Elsevier Churchill Liwingstone, 2008. p. 852-853.

VOLLALA, VR., JETTI, R. and SONI, S. High origin of an ulnar artery: development and surgical significance. Chang Gung Medical Journal, 2011, vol. 34, n. 6, p. 39-42. 